\title{
Histéresis y asimetría en delitos: un análisis de los robos a nivel colonia en la Zona Metropolitana de Guadalajara
}

\section{Hysteresis and asymmetry in crimes: An analysis of robberies at the neighborhood level in the Metropolitan Area of Guadalajara}

\author{
Willy W. Cortez*
}

\begin{abstract}
Resumen
Una de las características de la delincuencia que ha sido subestimada en estudios empíricos es su persistencia temporal y, por consiguiente, su respuesta asimétrica a cambios en sus variables explicativas. La importancia del efecto histéresis ha sido notada en diferentes estudios, en los que se argumenta que éste puede reducir de manera significativa la efectividad de las politicas de lucha contra el crimen. Utilizando las denuncias de diferentes tipos de robos a nivel colonia en la Zona Metropolitana de Guadalajara (ZMG), encontramos que dichos delitos presentan un fuerte componente de histéresis, y muestran un comportamiento asimétrico ante cambios en las condiciones económicas.
\end{abstract}

Palabras clave: histéresis en delincuencia; efectos asimétricos; delitos contra la propiedad; análisis econométrico; México.

\begin{abstract}
One of the characteristics of crime that has been underestimated in empirical studies is its persistence over time and, consequently, its asymmetric response to changes in its explanatory variables. The importance of the hysteresis effect has been noted in several studies, which argue that it can significantly reduce the effectiveness of anti-crime policies. Using reports of various types of robberies at the neighborhood

* Universidad de Guadalajara, CUCEA, Departamento de Métodos Cuantitativos. Dirección postal: Periférico Norte 799, Núcleo Los Belenes, Módulo Q-106 - Cátedras Conacyt. Correo electrónico:wcortez@cucea.udg.mx

Nota del autor: Quiero agradecer a Berenice Jaime y a Carlos O. Figueroa por el apoyo en la captura y procesamiento de la información estadística sobre la cual se sustenta este trabajo. También agradezco los comentarios de dos dictaminadores anónimos que ayudaron a mejorarlo. Asumo mi total responsabilidad por los errores y omisiones que puedan existir en el presente trabajo.
\end{abstract}


level in the Metropolitan Area of Guadalajara (ZMG), we find that these crimes have a strong hysteresis component, and display asymmetric behavior in response to changes in economic conditions.

Keywords: hysteresis in crime; asymmetric effects; property offenses; econometric analysis; Mexico.

\section{Introducción}

Uno de los problemas más complejos y costosos que enfrentan las metrópolis en América Latina es el de la delincuencia. Complejo, porque aún no se ha logrado determinar con precisión el o los factores críticos que inciden sobre ella: sospechosos hay muchos, así como muchas son las perspectivas teóricas utilizadas en su análisis. Costoso, porque los diferentes cálculos realizados muestran que éstos son de magnitudes realmente impresionantes. Soares y Naritomi (2010), por ejemplo, estiman que en el caso de los países de América Latina, los costos asociados al crimen pueden ascender hasta $7.5 \%$ del PIB regional. Esto representa más del doble del costo para Estados Unidos y más de tres veces el costo para los países de Asia. ${ }^{1}$ En otras palabras, comparado con otras regiones, el problema de la delincuencia y la violencia es mucho más agudo en América Latina que en otras regiones del mundo (Bourguignon, 2001; Soares y Naritomi, 2010).

Ciertamente, el problema de la delincuencia y la violencia asociada a ella no representa un fenómeno nuevo, sino más bien es una cuestión estructural de los países de la región. Ciudades como Río de Janeiro, São Paulo, Bogotá, Medellín, Lima, Buenos Aires, Ciudad de México y Guadalajara, entre otras, han enfrentado este problema en diferente medida desde hace mucho tiempo. A manera de ilustración -y manteniendo presentes las diferencias metodológicas utilizadas en su estimación-, se tiene, por ejemplo, que para el año 2011 Bogotá presentó una tasa de victimización de 25.1\%, mientras que Cali y Medellín tuvieron tasas de 20.9 y 18.4\%, respectivamen-

${ }^{1}$ Los costos de la delincuencia se pueden agrupar en tres categorías: los costos directos a los individuos, que afectan directamente a las víctimas, como pueden ser el monto de lo robado o la asistencia médica y/o psicológica; los costos directos a la sociedad, i.e., los que involucran el mantenimiento de organismos e instituciones públicas que ayudan a mantener el orden social, como el cuerpo policial, el sistema judicial, el sistema penitenciario, entre otros; y los costos indirectos, que son mucho más difíciles de medir y tienen que ver más con los costos asociados a los cambios de comportamiento de los individuos que con una mayor percepción de inseguridad. Los cambios de comportamiento pueden inducir, por ejemplo, menores niveles de inversión privada y mayores costos en sistemas de protección contra la delincuencia; en resumen, contribuyen a tomar decisiones que no son óptimas ni eficientes desde un punto de vista económico. 
te. Río de Janeiro, São Paulo y Buenos Aires, a su vez, presentan tasas de victimización de 22,16 y $32 \%$, respectivamente. En Lima, la tasa de victimización en 2014 fue de 34.5\%, mientras que en Santiago de Chile el porcentaje fue de 28\%. ${ }^{2}$ En el caso de México, en el 2008 las ciudades con las mayores tasas de victimización fueron la zona conurbada de México (Distrito Federal y Estado de México), las urbes fronterizas del norte del país como Ciudad Juárez y Tijuana, así como Guadalajara (ICESI, 2009).

Es importante tener en cuenta que la magnitud del problema de la criminalidad puede llegar a ser mucho más grave de lo que las estadísticas oficiales indican, porque existe evidencia de un alto grado de subreporte. Las diversas encuestas de victimización realizadas en América Latina sugieren que la tasa de denuncia de delitos ante el ministerio público es muy baja: va de 12\% (Río de Janeiro) a 46\% (Santiago de Chile). En México, las diferentes encuestas de victimización muestran que la tasa de denuncia puede ser tan baja como $21 \%$ (Navarro y Cortez, 2015). Si a esto se agregan las denuncias que no tienen averiguación previa, dan un porcentaje de cifra negra por arriba del 90 por ciento.

La persistencia de la alta incidencia delictiva en todas estas ciudades se ha dado a pesar de que las condiciones económicas en muchas de ellas muestran mejoras significativas y pese a la existencia de políticas anticrimen que las autoridades han implementado en sus respectivos países. ${ }^{3}$ Loureiro (2013a, 2013b) y Mocan y Bali (2005) argumentan que una de las posibles razones por la que las políticas anticrimen y las mejoras en las condiciones económicas no tienen la efectividad esperada es la existencia del efecto histéresis en el comportamiento criminal.

Tal efecto puede explicarse en los siguientes términos. Supongamos que un empeoramiento en las condiciones económicas en una región -o una

${ }^{2}$ La fuente en el caso de las ciudades colombianas es la Encuesta de Convivencia y Seguridad Ciudadana (DANE, 2012). Para São Paulo, Río de Janeiro y Buenos Aires es la Encuesta Internacional de Criminalidad y Victimización (ENICRIV) publicada en el año 2005 por la Organización de Estados Americanos (OEA, 2005). La fuente para Lima es la Estadística de Seguridad Ciudadana de 2015 (Instituto Nacional de Estadística, 2015). El dato para Santiago de Chile es la Encuesta Nacional Urbana de Seguridad Ciudadana del año 2013 (Ministerio del Interior y Seguridad Pública e Instituto Nacional de Estadísticas, 2013). En todos los casos la tasa de victimización es con respecto a la población mayor a 15 años.

3 Colombia, por ejemplo, implementó en 1995 un programa de combate a los narcotraficantes, auspiciado por el gobierno de Estados Unidos. Brasil, por su parte, en 2008 instauró el plan denominado Unidades de Policías Pacificadoras para reducir los delitos en las favelas. Chile también inició dos programas de prevención del delito en 1999: Plan Cuadrante y Comuna Segura. En el mejor de los casos, todos estos programas han dado resultados mixtos; es decir, no han tenido la efectividad esperada. Uno de los últimos esfuerzos de cooperación internacional quedó plasmado en 2012 con la creación del Sistema Interamericano contra el Crimen Organizado Transnacional, diseñado por la Organización de Estados Americanos (OEA). 
disminución en las medidas de disuasión de delitos- resulta en un aumento de la delincuencia en dicha región. Digamos que el aumento en la delincuencia fue de $x$ por ciento. Si las condiciones económicas o las medidas de disuasión se revierten en exactamente la misma magnitud, la delincuencia no se reduciría $x$ por ciento, sino en una magnitud menor. ¿Qué tanto menor?, eso va a depender del tamaño del efecto histéresis. Ahora que los determinantes regresaron a sus valores iniciales, el nivel de delincuencia no regresa a sus valores iniciales. Hasta cierto punto entonces, el rango de la delincuencia presente está vinculado con sus niveles pasados.

La persistencia del delito es explicada por diferentes motivos. Uno de ellos tiene que ver con el aumento de capital humano criminal relativo al capital humano legal de las personas que decidieron cometer el delito. Otro factor está asociado con la pérdida del sentimiento de culpa y vergüenza que existe luego de cometer el delito por primera vez. De igual manera, una reducción del costo del delito (debido al aprendizaje) aumenta la tasa de retorno de éste, lo que a su vez también puede explicar el efecto histéresis.

Mocan y Bali (2005) miden el efecto histéresis en los delitos contra la propiedad mediante la estimación del efecto asimétrico de los cambios en las condiciones económicas para Estados Unidos. En su estudio, ellos encuentran que el efecto de la tasa de desempleo sobre los delitos contra la propiedad es mayor en valor absoluto cuando éste aumenta que cuando declina. Loureiro (2013b), a su vez, también encuentra evidencia de un comportamiento asimétrico de la delincuencia para el caso de Estados Unidos. A diferencia de Mocan y Bali, Loureiro estima el comportamiento asimétrico de los delitos contra la propiedad a nivel estatal y utiliza el número de policías y el ingreso de los trabajadores poco calificados como variables que determinan los delitos contra la propiedad y los delitos violentos.

Hasta donde tenemos conocimiento, en el caso de México no existen estudios que estimen el efecto asimétrico de la delincuencia; por lo tanto, el presente trabajo representa una contribución en ese sentido. A diferencia de los estudios antes citados - que evalúan el efecto asimétrico en el tiempo-, nuestro análisis pretende calcular el efecto asimétrico en un análisis de sección cruzada, el cual permitirá identificar si el comportamiento criminal reacciona de diferente manera a los cambios en las condiciones económicas en diferentes espacios geográficos.

Para ello, se utiliza información sobre los robos a nivel colonia en la Zona Metropolitana de Guadalajara (ZMG). El estudio se concentra en analizar los robos por ser los ilícitos de mayor incidencia y porque, teóricamente, son los delitos que tienen una mayor sensibilidad a las condiciones económicas del espacio geográfico que se estudia. 
El resto del documento está compuesto por cinco secciones adicionales. La siguiente sección, la II, presenta una breve revisión de la literatura que sirve de sustento para el análisis empírico. La metodología se describe en la sección III, en la que se presenta el modelo econométrico, así como la descripción de las bases de datos y de las variables utilizadas. El análisis de estadísticas descriptivas se realiza en la sección IV, que contiene dos subsecciones: la primera caracteriza la delincuencia en la ZMG según el tamaño de colonia o municipio y el tipo de robo; la segunda evalúa la existencia de histéresis en los robos con mayor incidencia en tal metrópoli. En la sección $\mathrm{V}$ se analiza el grado de asimetría en estos delitos, controlando por variables sociales, demográficas y económicas. La última sección, la VI, presenta las principales conclusiones del presente estudio.

\section{Revisión de la literatura}

El efecto histéresis ha sido explicado desde diferentes perspectivas teóricas. Cada una de ellas enfatiza diferentes aspectos asociados al acto delictivo: desde el enfrentar el estigma social de ser catalogado como delincuente, pasando por los sentimientos de culpa y vergüenza inducidos por las normas sociales existentes, hasta el desarrollo de capital humano "criminal" generado por la actividad delictiva. Estos diferentes aspectos explican en diferente medida el grado de persistencia y asimetría de los delitos.

De acuerdo con Loureiro (2013a), la persistencia de la delincuencia obedece al efecto histéresis presente en el comportamiento criminal. Existen dos fuentes de histéresis: la externa y la interna. La primera es aquella que viene del estigma social que provoca que los delincuentes no encuentren empleo fácilmente o que reciban un salario más bajo que el que recibirían si no fueran criminales, lo cual hace que el capital social de estos individuos se deprecie a una mayor velocidad. Este estigma social en el mercado laboral, por lo tanto, propicia que los delincuentes continúen cometiendo delitos. La fuente interna, por otro lado, proviene de la pérdida del costo moral en el momento de cometer el delito y del aprendizaje de la "tecnología" criminal; estos dos elementos interactúan en el proceso de decidir cometer un delito o no, lo cual hace que la decisión sea cada vez menos difícil. De hecho, bajo este esquema se esperaría que las políticas sociales para reducir el delito sean más efectivas en delincuentes potenciales que en delincuentes consumados.

Weibull y Villa (2005) de manera similar desarrollan un modelo donde integran normas sociales con incentivos económicos para obtener un mode- 
lo de decisión del comportamiento humano. En éste se asume que existe una norma social contra la actividad criminal y que las desviaciones de dicha norma resultan en sentimientos de culpabilidad o vergüenza. La intensidad de los sentimientos es endógena en el sentido de que es más fuerte cuando la fracción de la población que obedece la norma es más grande. Por otro lado, una reducción gradual de las sanciones contra la actividad criminal puede debilitar la norma social contra el crimen.

El comportamiento criminal es el resultado tanto de las sanciones legales que se toman contra los criminales como de los sentimientos de culpabilidad y vergüenza que puedan sentir los individuos. Evidentemente, estos sentimientos resultan de la presión normativa implícita a vivir de actividades legales más que de ilegales. Cuando la presión normativa es débil, los sentimientos de culpabilidad y vergüenza son menores, y pueden generar un efecto histéresis en el comportamiento criminal.

En ambas explicaciones, tal comportamiento contiene un efecto histéresis, que de no ser tomado en cuenta -al igual que sus causas- puede provocar que programas de prevención del delito sean poco efectivos. Vergara (2009), por ejemplo, en su estudio para Chile encuentra que el aumento en la tasa de desempleo de fines de los noventa explica la mitad del incremento en la tasa del crimen durante ese periodo. Sin embargo, la tasa de delincuencia permaneció alta a pesar de la posterior reducción de la tasa de desempleo y pese a las políticas anticrimen implementadas.

Mocan y Bali (2005) proponen un modelo de optimización intertemporal del individuo, donde la histéresis se refleja en el comportamiento asimétrico de la actividad delincuencial. En el modelo, los individuos poseen dos tipos de capital humano: legal y criminal. El ingreso potencial en el sector legal (criminal) depende del nivel de capital humano legal (criminal) y su respectiva tasa de retorno. Ambos tipos de capital humano aumentan con la participación del individuo en su respectivo sector. Del mismo modo, cada tipo de capital humano es sujeto a depreciación cuando no es utilizado. Los niveles de actividad criminal y de capital humano criminal determinan la probabilidad de encarcelamiento. Si es encarcelado, la cantidad de ingreso que pierde el individuo depende de la magnitud del castigo que recibe en prisión.

Desde esta perspectiva, un empeoramiento en las condiciones económicas puede inducir a un individuo a aumentar el tiempo dedicado a actividades delincuenciales. La participación en actividades ilícitas aumenta el capital humano delincuencial, mientras que deprecia el capital humano legal. Tal fenómeno, que tuvo lugar durante la recesión, hace más difícil que el individuo retorne al sector legal inclusive a pesar de que la recesión haya termi- 
nado, pues no es el mismo después de ésta, ya que ahora es más proclive a cometer actos ilícitos.

Se debe notar que la decisión de cometer un delito no solamente obedece a factores económicos, también puede ser causada por factores no económicos, como pueden ser la disminución en las medidas de disuasión -reducción de la probabilidad de aprehender al delincuente o que se aminore su castigo-, o la disminución en la aversión al riesgo de los criminales, entre otros factores.

De acuerdo con Mocan y Bali (2005), el efecto histéresis se traduce en un comportamiento asimétrico de los delitos contra la propiedad ante cambios en las condiciones económicas. Es decir, la elasticidad de la actividad delincuencial con respecto a un deterioro de las condiciones económicas (o una reducción de las medidas de disuasión) es mayor que la elasticidad cuando las condiciones económicas mejoran (o las medidas de disuasión aumentan).

En su estudio, Mocan y Bali (2005) prueban la existencia de asimetría mediante la estimación del coeficiente de sensibilidad de los delitos contra la propiedad a cambios en las condiciones económicas (medido por la tasa de desempleo). En particular, asumen que la sensibilidad de los delitos contra la propiedad es mayor durante los periodos de recesión que durante los de expansión. En su modelo, los periodos de recesión son medidos por cambios positivos (o sin cambio) en la tasa de desempleo, mientras que los de prosperidad (o expansión) ocurren cuando existen cambios negativos en la tasa de desempleo. Ellos encuentran que el impacto del desempleo sobre los delitos contra la propiedad es mayor durante los periodos de recesión que durante los de expansión.

Es evidente que la actividad criminal en una ciudad o región no es explicada solamente por el efecto histéresis, sino que existen otros determinantes. Una gran proporción de los análisis de la delincuencia en las ciudades continúan la propuesta básica del modelo de Becker (1968), en el sentido de que los individuos delinquen si los beneficios esperados son mayores a los costos esperados de tal delito. Sin embargo, Glaeser et al. (1996) notan que uno de los hechos estilizados más importantes de la delincuencia en las ciudades, y que representa al mismo tiempo una gran incógnita, es la gran variabilidad espacial e intertemporal de las tasas de delincuencia; es decir, se observa una alta variabilidad en dichas tasas entre regiones o ciudades. Los autores sostienen que estas grandes diferencias no pueden ser explicadas por desigualdades en las condiciones económicas y sociales entre ciudades, ya que éstas sólo explican una pequeña proporción de las disimilitudes en los delitos. La única explicación admisible es que la decisión de un individuo 
de cometer un delito afecte la decisión de otro individuo de entrar a la actividad criminal; entonces, la actividad criminal de la ciudad difiere significativamente de la actividad criminal pronosticada por las características económico-demográficas de la urbe. En ese sentido, se argumenta que existe una covarianza positiva entre las decisiones delictivas de los individuos, $o$ lo que se denomina interacciones sociales entre los delincuentes y la actividad criminal en las ciudades.

Glaeser y Sacerdote (1999), por otro lado, identifican los factores que explican el hecho que la tasa de delincuencia sea mayor en las ciudades grandes que en las pequeñas. Ellos argumentan que esto se debe a la existencia de tres factores. Primero, que el retorno de la delincuencia es mayor en ciudades grandes: los delincuentes tienen la posibilidad no solamente de acceder a personas ricas, sino también de enfrentar una mayor población; ambas características hacen que el conjunto de probables víctimas sea mucho más grande. Segundo, las probabilidades de arresto por un delito cometido son menores en las ciudades grandes que en las pequeñas. Tercero, las ciudades grandes atraen a individuos que tienen tendencias delictivas. Hasta cierto punto, las ciudades grandes crean economías de aglomeración que pueden inducir mayor delincuencia. Es decir, mientras más grande es el número de potenciales víctimas, mayor es el incentivo que tienen los delincuentes para cometer actividades delictivas, ceteris paribus.

Ciertos estudios sobre la delincuencia en América Latina han tratado de asociar las altas tasas de criminalidad y violencia observadas en sus principales ciudades, al acelerado proceso de desarrollo urbano y económico. Sin embargo, la evidencia empírica sugiere que esto no es necesariamente cierto porque hay ciudades grandes que han logrado mantener sus niveles de criminalidad y violencia bajo control.

Por ejemplo, Gaviria y Pagés (1999) encuentran evidencia de que la tasa de victimización aumenta con el estatus socioeconómico de las familias. En el estudio, el tamaño de la ciudad y su crecimiento poblacional son variables que también sobresalen dentro del conjunto de variables explicativas adicionales de la delincuencia urbana. Para Gaviria y Pagés, el rápido crecimiento urbano está positivamente correlacionado con más crimen porque muchas de las ciudades de América Latina han sido incapaces de satisfacer las crecientes demandas de seguridad pública. Esta incapacidad obedece principalmente al proceso de urbanización desordenado y apresurado que exhiben las ciudades de dicha región.

Bourguignon (2001), a su vez, concluye que la gran variabilidad en las tasas de delincuencia observada no está ligada al nivel de desarrollo del país o de la ciudad, sino más bien al desarrollo de otras condiciones como son la 
pobreza y la desigualdad. Estos dos factores, sin embargo, están interrelacionados con los factores sociales y culturales.

Existe cierto debate acerca de la importancia relativa de la pobreza y la desigualdad como factores explicativos del crimen y violencia. Los estudios iniciales afirmaban que tanto la pobreza como la desigualdad eran los principales determinantes de la actividad criminal: los aumentos en la pobreza o en la desigualdad inducían los incrementos en la actividad criminal (Bourguignon, 2001).

Pero las teorías existentes predicen resultados totalmente contradictorios en lo que concierne a identificar quiénes son las víctimas: ¿los pobres o los ricos? En ese sentido, la relación positiva entre desigualdad y delitos no identifica quiénes son las víctimas. Se presume que las personas o familias ricas o con mayores niveles de ingreso son las víctimas. Sin embargo, esto último ocurre siempre y cuando las personas ricas no aumenten sus medidas de autoprotección, no disminuyan sus actividades de riesgo, o no ejerzan ningún tipo de presión sobre las autoridades demandando mayor protección. El resultado cambia si los individuos en la parte superior de la distribución deciden aumentar sus medidas de seguridad y autoprotección, demandan mayor vigilancia policial, o reducen sus actividades de riesgo. En este último caso, un aumento en la desigualdad se ve reflejado en un aumento en la tasa de victimización en las familias de menores ingresos. A nivel agregado, estos efectos diferenciados no se observan. Sólo se evidencia que un aumento en la pobreza o desigualdad está positivamente relacionado con la delincuencia. Estos efectos sólo se pueden observar cuando la unidad de análisis es pequeña.

Patterson (1991) sostiene que un punto importante en trabajos empíricos, y que puede llevar a resultados diferentes, es la unidad de análisis: si es pequeña, tiene la ventaja de que otorga un marco de análisis con mayor significado para muchos de los conceptos utilizados; de igual manera, permite mediciones menos ambiguas de la variable dependiente. Adicionalmente, cuando la unidad de medida es pequeña se pueden medir con mayor certeza algunas variables que pueden estar asociadas con la distribución espacial de la delincuencia, a saber: movilidad residencial, heterogeneidad étnica o racial, integración en la colonia, composición familiar y/o densidad poblacional, entre otras variables. Entre sus principales hallazgos, Patterson (1991) encuentra que la pobreza y la alta densidad poblacional aunadas son más significativas en explicar los delitos violentos, mientras que la desigualdad no lo es. El robo a casa habitación es más común en barrios pobres y en áreas caracterizadas por una mayor desigualdad. En resumen, la respuesta a la pregunta de quiénes son las víctimas sólo se puede obtener si 
los estudios empíricos consideran unidades de análisis pequeñas, como pueden ser manzanas, barrios o colonias.

Demombynes y Özler (2002), a su vez, hacen notar algunas desventajas adicionales en estudios de sección cruzada entre unidades de análisis agregadas, como pueden ser países, estados o ciudades. En primer lugar, los procesos que generan las tasas de delincuencia en los distintos países, ciudades o estados son probablemente muy diferentes unos de otros, por lo que las implicaciones de política pública de estos estudios pueden resultar sesgadas en el mejor de los casos o de muy poca utilidad. Un segundo elemento es que las definiciones de los indicadores de bienestar y de delincuencia en los distintos países no necesariamente son comparables. En tercer lugar, los marcos institucionales y legales entre países son muy diferentes, lo cual impide hablar de políticas homogéneas entre éstos. Por último, tales estudios tratan a los delitos como mercados cerrados, de tal manera que las interacciones potenciales entre áreas vecinas no son analizadas.

Esta breve e incompleta revisión bibliográfica permite identificar algunas variables claves asociadas a la delincuencia; a saber, pobreza (o riqueza), desigualdad, tamaño de la localidad y ciertas características demográficas, entre otras.

\section{Metodología}

\section{III.1. Modelo econométrico}

Basado en la literatura, se propone el siguiente modelo para evaluar la existencia de asimetría en los delitos contra la propiedad. Este modelo es una versión modificada del modelo de asimetría propuesto por Mocan y Bali (2005). En nuestro caso, la unidad de análisis es la colonia y el análisis es de sección cruzada. La principal causa de hacer esta modificación es la falta de información temporal de las variables a nivel colonia. Por consiguiente, se propone el siguiente modelo para cada tipo de delito:

$$
y_{i j}=f\left(u_{i j}^{+}, u_{i j}^{-}, x_{i j}, z_{i j}, v_{i j}\right)
$$

donde $y_{i j}$ representa la variable dependiente (delitos) en la colonia $i$ del municipio $j$.

$$
u_{i j}^{+}=\left\{\begin{array}{rl}
u_{i j} & \text { si } u_{i j} \geq \bar{u}_{j} \\
0 & \text { si } u_{i j}<\bar{u}_{j}
\end{array} \quad \forall j=1,2,3,4\right\} \text {, }
$$




$$
u_{i}^{-}=\left\{\begin{array}{rl}
u_{i j} & \text { si } u_{i j}<\bar{u}_{j} \\
0 & \text { si } u_{i j} \geq \bar{u}_{j}
\end{array} \quad \forall j=1,2,3,4\right\}
$$

Además, $\bar{u}_{j}$ es la media del desempleo en el municipio $J ; u^{+}, u^{-}$representan la tasa de desempleo en la colonia $i$ cuando está por arriba o por debajo de la media del municipio donde están ubicadas. Por otro lado, $x_{i}$ es la matriz de variables sociodemográficas; $z_{i}$, a su vez, representa la matriz de indicadores de bienestar o riqueza de las familias en las colonias, mientras que la matriz $v_{i}$ agrupa a las variables sociales como condición de migración, religión, etc. La hipótesis de asimetría e histéresis se confirma cuando los parámetros estimados de $u^{+}$y $u^{-}$resultan ser estadísticamente significativos y diferentes entre sí.

Como se mencionó en la introducción, una de las preguntas centrales que el presente trabajo trata de responder es si se puede detectar un comportamiento asimétrico de la delincuencia en un análisis de sección cruzada. Es decir, si las diferencias existentes en las condiciones económicas entre las colonias son lo suficientemente significativas como para determinar patrones de comportamiento diferenciado de la delincuencia.

Del universo de delitos denunciados ante el Ministerio Público, se seleccionaron aquellos que (teóricamente) son más sensibles al desempeño económico de la comunidad: los robos. El presente análisis sólo considera los reportados con más frecuencia, como los robos de automóviles y autopartes (rauto), ${ }^{4}$ a personas (rp) y a casas (rcasa). Como se mencionó, el análisis se realiza para cuatro de los nueve municipios que conforman la Zona Metropolitana de Guadalajara. ${ }^{5}$ Según el Censo de Población y Vivienda, 2010 (INEGI, 2010), estos cuatro municipios aglutinan 1289 colonias. Se debe resaltar que muchas colonias no presentan denuncias por delitos, por lo que no se incluyen en el análisis empírico.

${ }^{4}$ Incluye robo a carga pesada, a vehículos particulares, vehículos de carga liviana, motocicletas, al interior de vehículos, y de autopartes.

${ }_{5}^{5}$ La Zona Metropolitana de Guadalajara (ZMG) en 2015 contenía 4.5 millones de personas. Tiene una superficie de $6134.7 \mathrm{~km}^{2}$, lo cual implica una densidad poblacional de 733.3 habitantes por $\mathrm{km}^{2}$. Los nueve municipios que la integran son: Guadalajara, Zapopan, San Pedro Tlaquepaque, Tonalá, Tlajomulco de Zúñiga, El Salto, Ixtlahuacán de los Membrillos, Juanacatlán y Zapotlanejo (este último se integró en 2015). El municipio más poblado es Guadalajara, con 1.5 millones de habitantes; la urbe se ubica a unos $540 \mathrm{~km}$ al noroeste de la Ciudad de México (INEGI, 2016). 


\section{III.2. Bases de datos}

La información sobre los tipos de robos se obtuvo de las denuncias presentadas por las víctimas ante el Ministerio Público del Estado. Éstas son publicadas mensualmente por la Oficina de Estadísticas de la Fiscalía Central de la Procuraduría General de Justicia del Estado de Jalisco (PGJEJ). La información publicada por la PGJEJ identifica la colonia donde ocurrió el delito dentro de los cuatro municipios considerados en la ZMG: Guadalajara, Zapopan, Tlaquepaque y Tonalá. Por otro lado, toda la información sociodemográfica y económica, así como los indicadores de bienestar de las familias, provienen del Censo de Población del año 2010. Como se sabe, la información que proporciona el Instituto Nacional de Geografía y Estadística (INEGI) está a nivel AGEB, por lo que se tuvo que hacer la agregación de las AGEB para obtener los datos a nivel colonias.

\section{III.3. Definición de variables}

Es importante recalcar que aun cuando se tiene información sobre los tipos de robos para el periodo 2009-2013, a nivel colonia sólo se cuenta con información de las variables sociodemográficas y económicas y de bienestar para el año 2010, lo cual constituye una gran limitación del presente análisis empírico. Esta falta de información limitó el periodo de análisis a un solo año, 2010.

Como indicador del desempeño económico utilizamos la tasa de desempleo en las colonias. Para evaluar el impacto diferenciado de ésta sobre la delincuencia, se utilizan las series $u_{i j}^{+}$y $u_{i j}^{-}$definidas anteriormente. El tamaño de la colonia se mide de dos maneras. Una es mediante el uso del logaritmo natural del número de personas que viven en ella. Alternativamente, se agrupan las colonias en seis tamaños mediante una variable categórica. Se definen seis categorías: 1) menor a 1000 habitantes, 2) entre 1000 y 1999 habs., 3) entre 2000 y 2999 habs., 4) entre 3000 y 4999 habs., 5) entre 5000 y 10000 habs., y 6) más de 10000 habs. La variable educación, por otro lado, se mide como el número de personas mayores de 15 años que tienen educación primaria, educación secundaria y al menos preparatoria. Esta variable es un proxy no solamente del nivel cultural/educativo de la población que vive en la colonia, sino también puede ser tomado como un indicador del nivel de ingreso de la población. Esto último basado en la teoría del capital humano que establece que el rango de ingreso de las personas depende de su nivel educativo. Adicionalmente, en la medida en que 
las colonias muestran diferente distribución educativa, ésta también puede ser considerada una variable proxy de la distribución del ingreso.

La variable edad, a su vez, se mide como el número de personas en determinado rango de edad que viven en las colonias. Se definen cuatro grupos: i) menores a 15 años, ii) entre 15 y 24 años, iii) entre 25 y 64 años, y iv) personas mayores a 65 años. Acerca de la variable de bienestar, se utiliza el número de viviendas que cuentan con electricidad, agua entubada, drenaje, automóvil, internet, computadora, televisor, artículos electrodomésticos, entre otros. Mediante la técnica de componentes principales, todas estas variables se reducen a un índice compuesto que sirve como proxy del nivel de bienestar o riqueza en las colonias, que denominamos bienestar. Finalmente, para controlar por diferencias institucionales entre municipios - entre las cuales figuran el grado de eficiencia o de corrupción administrativa-, y dado que cada municipio controla su propia policía, se utiliza una variable discreta que toma diferentes valores según el municipio en el cual está localizada la colonia.

\section{Hechos estilizados de los delitos en la ZMG}

\section{IV.1. Caracterización de los delitos}

Según los datos publicados por la PGJEJ (2016), en el 2010 el municipio de Guadalajara fue el que presentó la tasa de delitos totales más alta de los cuatro considerados en el análisis. Fue seguido por Tlaquepaque, Zapopan y Tonalá (en ese orden). Un análisis de la distribución de las colonias por tasa de delitos totales indica que la gran mayoría presenta tasas menores a 20. En efecto, 87, 91, 97 y $92 \%$ de ellas presentan tasas de delitos menores a 20 por cada mil habitantes en Guadalajara, Tlaquepaque, Tonalá y Zapopan, respectivamente.

En el Cuadro 1 se observa la tasa de delitos totales por municipio y por tamaño de colonia. La primera característica que sobresale es que, con excepción de Tonalá, las colonias pequeñas -i.e., con menos de 1000 habitantespresentan tasas de delitos mayores respecto a las colonias de mayor tamaño. ${ }^{6}$ Una segunda característica es que el municipio de Guadalajara tiene tasas de delitos altas en colonias de hasta 5000 habitantes. Estas tasas son mayores a

${ }^{6}$ El cálculo de la tasa de delitos reveló que en colonias muy pequeñas la tasa fue muy superior a 100 delitos por cada 1000 habitantes, lo cual es irreal para la ZMG. En total fueron 17 colonias las que se tuvieron que eliminar del análisis porque inflaban los promedios de las tasas delictivas; entre ellas están las ubicadas en la zona industrial y la colonia donde se encuentra la Nueva Central de Autobuses, donde viven pocas personas. 


\section{Cuadro 1}

Tasa de delitos totales por municipio y tamaño de colonia, 2010 (por cada mil habitantes)

\begin{tabular}{lcccc}
\hline Tamaño de colonia & Guadalajara & Tlaquepaque & Tonalá & Zapopan \\
\hline$<1000$ & 20.2 & 14.5 & 7.8 & 16.6 \\
$1000-2000$ & 12.4 & 8.6 & 5.6 & 8.9 \\
$2000-3000$ & 12.7 & 6.5 & 5.2 & 7.4 \\
$3000-5000$ & 10.9 & 9.2 & 5.1 & 8.5 \\
$5000-10000$ & 8.6 & 8.8 & 6.5 & 7.4 \\
$>=10000$ & 8.8 & 6.5 & 5.9 & 7.5 \\
Promedio & 11.5 & 9.9 & 6.5 & 10.4 \\
Obs. & 218 & 117 & 99 & 285 \\
\hline
\end{tabular}

Fuente: Elaboración propia con base en información proporcionada por la Fiscalía Central de la Procuraduría General de Justicia del Estado de Jalisco (PGJEJ, 2016).

las de los demás municipios de igual tamaño. Tercero, Tonalá, el municipio con más carencias, o con el menor nivel de bienestar, presenta las tasas más bajas entre los cuatro municipios de la ZMG. Estas disimilitudes intermunicipales en las tasas delictivas totales pueden deberse a diferencias reales en el nivel de inseguridad o en las tasas de denuncias. Con la información disponible no podemos determinar cuál de estas dos hipótesis es la verdadera.

Durante el periodo 2009-2013 los delitos contra la propiedad representaron cerca del $40 \%$ del total de delitos en la $\mathrm{ZMG}^{7}$ El municipio de Guadalajara es el que presenta los índices de delitos contra la propiedad más elevados, como se puede observar en la Gráfica 1. Le siguen Zapopan, Tlaquepaque y Tonalá.

También se observa que en los cuatro municipios los robos presentan una tendencia creciente hasta 2011. Entre 2011 y 2013 éstos caen paulatinamente, pero sin llegar a los niveles de 2009.

De los robos, los de vehículos, a casas y a personas fueron los de mayor frecuencia con $16.1,9.5$ y $4.5 \%$, respectivamente. ${ }^{8}$ El Cuadro 2 desglosa los robos más frecuentes y el total de delitos contra la propiedad por tamaño de colonia. Se presenta el número promedio de robos, así como la tasa de cada modalidad. De los resultados expuestos se puede inferir que el de autos es

${ }^{7}$ En el presente análisis se consideran como delitos contra la propiedad a la suma de todos los tipos de robos, incluyendo robo a instituciones financieras, a cajeros automáticos, a cuentahabientes, a negocios, a tiendas de autoservicios, etcétera.

${ }^{8}$ Los porcentajes se refieren al total de delitos en la Zona Metropolitana de Guadalajara (ZMG) en promedio durante el periodo 2009-2013. 


\section{Gráfica 1}

ZMG: delitos contra la propiedad

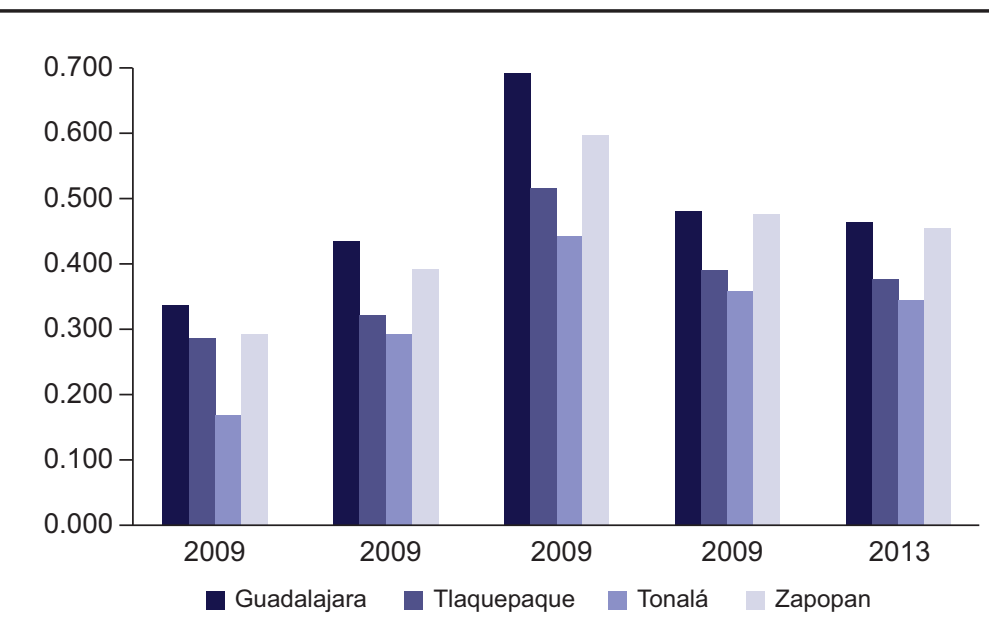

Fuente: Estimaciones propias con base en información publicada por la Fiscalía Central de la Procuraduría General de Justicia del Estado de Jalisco (PGJEJ, 2016).

el robo que ocurre con más frecuencia, seguido por el perpetrado a casas y a personas. Es importante destacar que el patrón de comportamiento observado en los delitos totales se repite en el caso de robos. Es decir, el número de delitos está positivamente correlacionado con el tamaño de la colonia, mientras que la tasa de delitos muestra una relación inversa con el tamaño de la colonia.

Por otro lado, en el Cuadro 3 se detalla la población por tamaño de colonia y por municipio. Se puede observar que la mayor proporción de personas vive en colonias de más de 5000 personas. En promedio, éstas aglutinan más del $60 \%$ de la población en cada uno de los municipios considerados. En términos poblacionales, Guadalajara es el municipio más numeroso, seguido por Zapopan. Por su parte, Tlaquepaque y Tonalá son municipios mucho más pequeños que los dos anteriores.

A continuación se presentan los valores medios de las variables utilizadas en el análisis empírico por municipio para el año 2010 (Cuadro 4). Según se observa, Guadalajara es el que presenta los índices de robos más altos, seguido por Tlaquepaque y Zapopan; en último lugar está Tonalá. En términos de la tasa de desempleo, Tonalá y Tlaquepaque presentan tasas mayores a las de Guadalajara y Zapopan. 


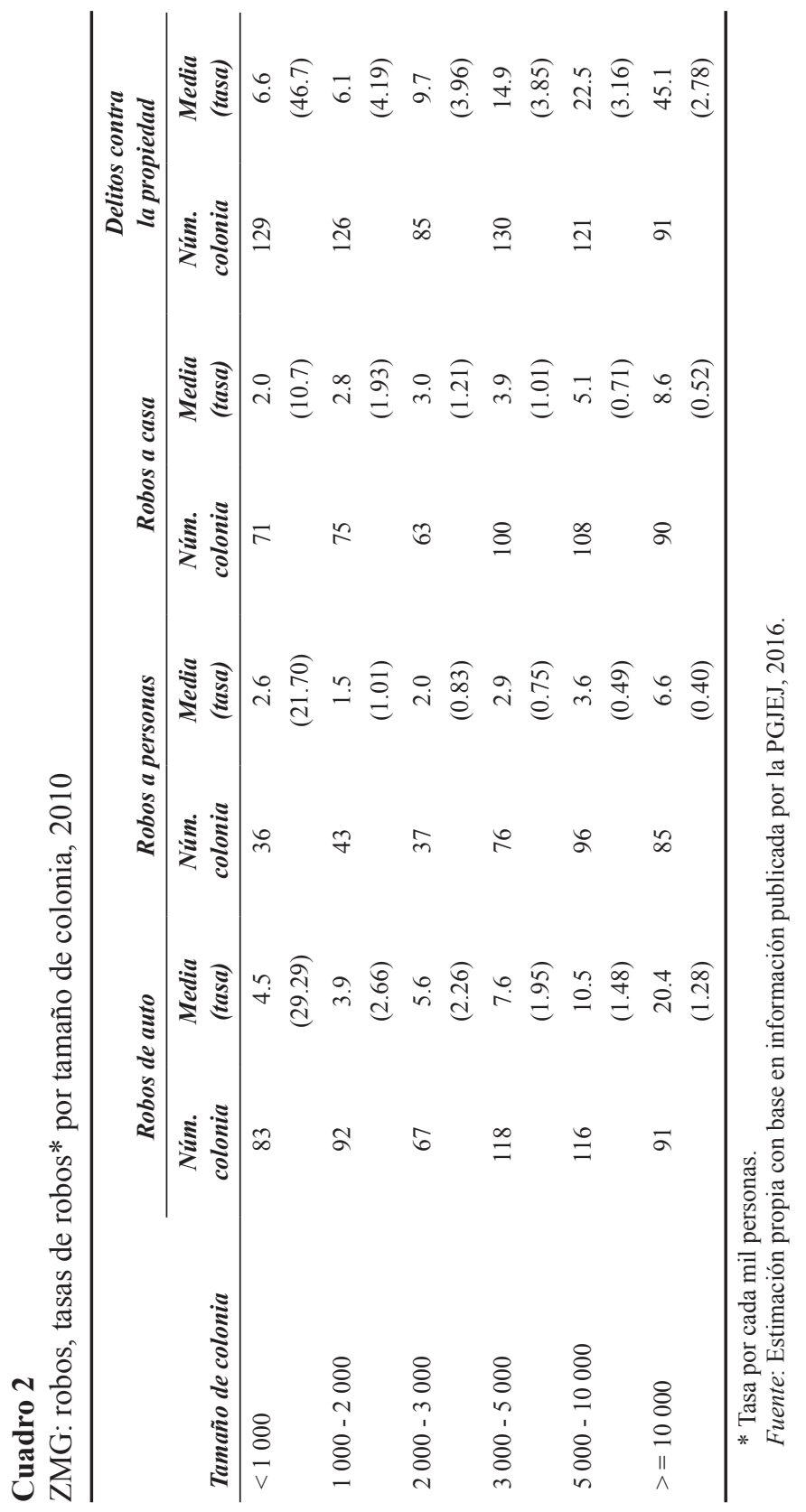




\section{Cuadro 3}

Población por tamaño de colonias y municipio

\begin{tabular}{lcccc}
\hline Tamaño de colonia & Guadalajara & Tlaquepaque & Tonalá & Zapopan \\
\hline$<1000$ & 19461 & 31576 & 34132 & 82676 \\
\multirow{2}{*}{$1000-2000$} & $(1.3)$ & $(5.4)$ & $(7.6)$ & $(6.8)$ \\
& 61606 & 48140 & 40217 & 119426 \\
$2000-3000$ & $(4.1)$ & $(8.2)$ & $(8.9)$ & $(9.8)$ \\
& 90428 & 48197 & 51049 & 123051 \\
$3000-5000$ & $(6.0)$ & $(8.2)$ & $(11.3)$ & $(10.1)$ \\
& 190776 & 105018 & 54296 & 205156 \\
$5000-10000$ & $(12.7)$ & $(17.9)$ & $(12.0)$ & $(16.8)$ \\
& 368844 & 172009 & 91144 & 272323 \\
$>10000$ & $(24.5)$ & $(29.3)$ & $(20.2)$ & $(22.3)$ \\
& 776383 & 181370 & 180866 & 420545 \\
Total población & $(51.5)$ & $(30.9)$ & $(40.0)$ & $(34.4)$ \\
& 1488037 & 586310 & 451704 & 1223177 \\
\hline
\end{tabular}
2010).

Fuente: Elaboración propia con base en el Censo de Población y Vivienda, 2010 (INEGI,

Otras características de los municipios tienen que ver con el tamaño de la población femenina (lpobfem), el número de hogares uniparentales femenino (lphogj_f) y la proporción de personas mayores de 65 años (t_pob65ymas). En cada una de las variables mencionadas Guadalajara ocupa el primer lugar.

En lo que respecta a la educación, tanto Guadalajara como Zapopan son los municipios con los niveles educativos más altos: presentan bajos porcentajes de personas con niveles educativos con secundaria o menos, mientras que exhiben mayores proporciones de personas con estudios por arriba de preparatoria.

El siguiente grupo de variables que se incluyen en el Cuadro 4 mide la proporción de viviendas con acceso a infraestructura pública como agua potable, electricidad y piso diferente de tierra (con respecto al total de viviendas). Los datos indican que Tonalá y Tlaquepaque son los municipios con un mayor número de viviendas que no tienen acceso a estos bienes públicos. Por último, se presentan algunos indicadores de riqueza de las viviendas como son posesión de bienes electrodomésticos y otros bienes como televisión, lavadora, computadora, teléfono fijo, celular, acceso a internet y automóvil. Los datos muestran que la mayor proporción de viviendas con estos bienes se encuentra tanto en Guadalajara como en Zapopan. Tonalá es el municipio con las tasas de riqueza más bajas, seguido por Tlaquepaque. 


\section{Cuadro 4}

Estadísticas descriptivas, 2010

\begin{tabular}{lcccc}
\hline Variable & Guadalajara & Tlaquepaque & Tonalá & Zapopan \\
\hline lrobauto10 & 2.054 & 1.422 & 0.943 & 1.355 \\
lrp10 & 1.191 & 0.762 & 0.668 & 0.701 \\
lrobcasa10 & 1.277 & 1.099 & 0.857 & 1.066 \\
ldelprop10 & 2.627 & 2.004 & 1.461 & 1.750 \\
t_des & 0.038 & 0.049 & 0.061 & 0.050 \\
lpobfem & 7.417 & 6.408 & 5.787 & 6.083 \\
lphogj_f & 6.668 & 5.458 & 4.678 & 5.071 \\
t_pob65ymas & 5.410 & 3.700 & 2.877 & 3.484 \\
t_p15ym_se (\%) & 2.03 & 3.72 & 3.03 & 2.1 \\
t_p15primsec (\%) & 32.3 & 38.2 & 40.16 & 25.43 \\
t_p18ym_prepa (\%) & 36.51 & 25.62 & 18.39 & 41.23 \\
t_pder_imss & 0.515 & 0.519 & 0.425 & 0.456 \\
t_vpisodt & 0.831 & 0.734 & 0.708 & 0.753 \\
t_vcelec & 0.851 & 0.775 & 0.747 & 0.779 \\
t_vaguadv & 0.844 & 0.712 & 0.597 & 0.737 \\
t_vtv & 0.842 & 0.768 & 0.741 & 0.771 \\
t_vrefri & 0.824 & 0.721 & 0.696 & 0.753 \\
t_vlav & 0.743 & 0.634 & 0.614 & 0.691 \\
t_vpc & 0.444 & 0.307 & 0.226 & 0.490 \\
t_vtel & 0.634 & 0.434 & 0.362 & 0.575 \\
t_vcel & 0.713 & 0.636 & 0.615 & 0.696 \\
t_vinter & 0.232 & 0.149 & 0.421 \\
t_vauto & 0.453 & 0.418 & 0.586 \\
\hline & 0.355 & & 0.56 & 2016 \\
\hline
\end{tabular}

Fuente: Estimaciones propias con base en información publicada por la PGJEJ, 2016 y en el Censo de Población y Vivienda, 2010 (INEGI, 2010). 


\section{IV.2. Histéresis}

En esta sección se evalúa el grado de histéresis para cada uno de los tres tipos de robo considerados. Asumiendo que los delitos son un fenómeno social con dinámica propia y que no depende de ningún factor, la mejor aproximación para pronosticar éstos sería modelarlos en función de su valor en años previos; es decir, como un proceso autorregresivo. El coeficiente del componente autorregresivo mide el efecto histéresis. Para ello se proponen dos modelos. El primero es un autorregresivo de orden 1, AR(1), con la finalidad de evaluar el grado de relación de los delitos de un año con respecto al año anterior. Este ejercicio se realiza para cada uno de los años del periodo 2009-2013. El segundo modelo es un autorregresivo de orden $k, \operatorname{AR}(k)$. Este último trata de medir el impacto de los delitos en los años 2009-2012 sobre los delitos en 2013. Entonces, los modelos propuestos son:

$$
\begin{gathered}
y_{i t}=\mu+\rho_{1} y_{i, t-1}+\varepsilon_{i} \\
y_{i t}=\mu+\rho_{1} y_{i, t-1}+\rho_{2} y_{i, t-2}+\ldots+\rho_{k} y_{i, t-k}+\varepsilon_{i}
\end{gathered}
$$

donde $\rho$ representa el coeficiente que mide el efecto histéresis (o persistencia) del delito en periodos pasados sobre el actual, el subíndice $i$ se refiere al tipo de delito y $t$ se refiere al año.

El Cuadro 5 presenta el efecto histéresis para cada uno de los delitos considerados utilizando la ecuación [2]. Los resultados sugieren algunas conclusiones importantes. Primero, el efecto histéresis es bastante fuerte en los tres tipos de robos. Segundo, el efecto inercial es más fuerte en el caso de robo a automóviles, mientras que el robo a casas presenta los efectos más bajos. Aun en este último caso, el efecto es bastante significativo. Tercero, el coeficiente de un año con respecto al anterior es estadísticamente significativo en todos los casos.

\section{Cuadro 5}

Histéresis en robos (elasticidad)

\begin{tabular}{cccc}
\hline & Auto & Personas & Casa \\
\hline$\rho_{10 / 09}$ & $0.857^{* * *}$ & $0.788^{* * *}$ & $0.645^{* * *}$ \\
$\rho_{11 / 10}$ & $0.813^{* * *}$ & $0.697^{* * *}$ & $0.669^{* * *}$ \\
$\rho_{12 / 11}$ & $0.846^{* * *}$ & $0.693^{* * *}$ & $0.682^{* * *}$ \\
$\rho_{13 / 12}$ & $0.837^{* *}$ & $0.734^{* * *}$ & $0.664^{* * *}$ \\
\hline
\end{tabular}

$* \mathrm{p}<0.05, * * \mathrm{p}<0.01, * * * \mathrm{p}<0.001$

Fuente: Elaboración propia con base en datos proporcionados por la PGJEJ, 2016. 


\section{Cuadro 6}

Efecto histéresis

\begin{tabular}{|c|c|c|c|c|}
\hline & $\begin{array}{c}\text { Robo a autos } \\
b / p\end{array}$ & $\begin{array}{c}\text { Robo a } \\
\text { personas } \\
b / p\end{array}$ & $\begin{array}{c}\text { Robo a casa } \\
b / p\end{array}$ & $\begin{array}{c}\text { Delitos contra } \\
\text { la propiedad } \\
\text { b/p }\end{array}$ \\
\hline lrobauto12 & $\begin{array}{c}0.24935^{* * *} \\
(0.000)\end{array}$ & & & \\
\hline 1robauto11 & $\begin{array}{l}0.23495 * * * \\
(0.000)\end{array}$ & & & \\
\hline lrobauto10 & $\begin{array}{l}0.28346^{* * * *} \\
(0.000)\end{array}$ & & & \\
\hline 1robauto09 & $\begin{array}{l}0.15050^{* * *} \\
(0.001) \\
\end{array}$ & & & \\
\hline $\operatorname{lrp} 12$ & & $\begin{array}{l}0.36976^{* * * *} \\
(0.000)\end{array}$ & & \\
\hline lrp11 & & $\begin{array}{l}0.25550^{* * * *} \\
(0.000)\end{array}$ & & \\
\hline lrp10 & & $\begin{array}{l}0.15535^{* *} \\
(0.007)\end{array}$ & & \\
\hline lrp09 & & $\begin{array}{r}0.09997 \\
(0.076) \\
\end{array}$ & & \\
\hline lrobcasa 12 & & & $\begin{array}{l}0.28534 * * * \\
(0.000)\end{array}$ & \\
\hline lrobcasa11 & & & $\begin{array}{l}0.29958^{* * * *} \\
(0.000)\end{array}$ & \\
\hline |robcasa10 & & & $\begin{array}{l}0.18242 * * \\
(0.008)\end{array}$ & \\
\hline 1robcasa09 & & & $\begin{array}{r}0.11425 \\
(0.061) \\
\end{array}$ & \\
\hline 1delprop12 & & & & $\begin{array}{l}0.33819^{* * * *} \\
(0.000)\end{array}$ \\
\hline ldelprop11 & & & & $\begin{array}{l}0.22973 * * * \\
(0.000)\end{array}$ \\
\hline 1delprop10 & & & & $\begin{array}{l}0.22365^{* * *} \\
(0.000)\end{array}$ \\
\hline 1delprop09 & & & & $\begin{array}{c}0.08044 * \\
(0.023)\end{array}$ \\
\hline Constante & $\begin{array}{l}0.31480 * * * \\
(0.000)\end{array}$ & $\begin{array}{c}0.93961 * * * \\
(0.000)\end{array}$ & $\begin{array}{c}0.43741^{* * *} \\
(0.000)\end{array}$ & $\begin{array}{l}0.63449^{* * * *} \\
(0.000)\end{array}$ \\
\hline $\mathrm{R}^{2}$ ajustada & 0.75623 & 0.65507 & 0.51563 & 0.82504 \\
\hline $\mathrm{N}$ & 408 & 190 & 252 & 524 \\
\hline $\mathrm{AIC}$ & 567.9 & 226.9 & 434.2 & 631.4 \\
\hline
\end{tabular}

$* \mathrm{p}<0.05, * * \mathrm{p}<0.01, * * * \mathrm{p}<0.001$. P-value entre paréntesis.

Fuente: Estimaciones propias. 
En la medida en que los robos están expresados en logaritmos, el coeficiente autorregresivo también puede ser interpretado como la elasticidad temporal del robo (con respecto al periodo anterior). Por ejemplo, la sensibilidad del robo de autos en el 2013 con respecto al 2012 es de 83 por ciento.

En el Cuadro 6 se muestra un estimado de la persistencia de los robos. Este efecto histéresis puede durar hasta cuatro años (como en el caso de robos de automóviles). En cuanto a los perpetrados a casa y a personas, la persistencia es de tres años. Estos resultados sugieren que colonias caracterizadas por una alta tasa de delincuencia, que tuvieron una elevada incidencia de robos en un año determinado, es muy probable que la sigan teniendo en años posteriores.

\section{Análisis econométrico}

En esta sección se evalúa la hipótesis de histéresis (o asimetría) de los diferentes delitos contra la propiedad, controlando por las variables sociodemográficas y económicas identificadas en la literatura como factores que inciden en la delincuencia. Para ello retomamos la ecuación [1] y especificamos el siguiente modelo lineal:

$$
y_{i}=\alpha+\beta_{1} u_{i}^{+}+\beta_{2} u_{i}^{-}+x_{i k} \sigma_{\mathrm{k}}+\mathrm{z}_{\mathrm{il}} \delta_{1}+v_{i m} \gamma_{m}+M_{i j} \theta_{j}+T_{i s} p_{s}+\varepsilon_{i}
$$

Bajo la presencia de asimetría se espera que los parámetros $\beta_{1}$ y $\beta_{2}$ sean estadísticamente diferentes; es decir, los delitos contra la propiedad responden de manera distinta en aquellas colonias que presentan tasas de desempleo por arriba de la media de su municipio respecto de las que presentan tasas de desempleo por debajo de dicha media. Se toma la media municipal del desempleo porque se asume que existen diferencias institucionales entre municipios, lo cual puede resultar en una dinámica diferente en el comportamiento delincuencial.

Como se comentó líneas arriba, $x_{i k}, z_{i l}, v_{i m}$ son vectores de variables sociales, demográficas y culturales de las colonias; $M_{j}$ es una variable categórica que permite controlar por el municipio ( $j=$ Tlaquepaque, Tonalá y Guadalajara), mientras que $T_{s}$ es una variable categórica que define el tamaño de la colonia $(s=2,3,4,5$ y 6$)$. La constante captura el efecto del municipio de Guadalajara y colonias pequeñas (menores a 1000 habitantes). Por su parte, $\varepsilon_{1}$ es el término de error que se tiene en una distribución normal y además $\sim$ i.i.d. $\left(0, \sigma^{2}\right)$. 
Uno de los potenciales problemas que afectan las estimaciones de sección cruzada es el de la heteroscedasticidad. Esto ocurre cuando la varianza del término de error no es constante, ya que ésta es una función de alguna de las variables independientes. ${ }^{9} \mathrm{Si}$ se utilizan mínimos cuadrados ordinarios para estimar los parámetros, aun cuando estén insesgados, éstos no poseen varianza mínima, es decir, son ineficientes. Esto trae como consecuencia que las pruebas de hipótesis no sean confiables (Johnston y DiNardo, 1997).

Luego de realizar la prueba de White y de Breusch-Pagan se determinó que en efecto, la estimación de la ecuación [3] por MCO genera parámetros ineficientes. El problema se atacó de dos maneras. La primera consistió en aplicar el logaritmo a la variable dependiente, con lo cual se redujo la heteroscedasticidad. En la segunda, la estimación de los parámetros se hizo incorporando el estimador robusto de la matriz de varianza-covarianza, con lo cual el problema de heteroscedasticidad se redujo aún más. Como se detalla más adelante, tal problema se redujo significativamente, lo cual permite hacer inferencias estadísticas acerca de la significancia de los parámetros estimados.

El Cuadro 7 presenta los diferentes modelos estimados para el caso de robo de automóviles y autopartes. En primer lugar, se encuentra evidencia robusta de la existencia de asimetría. En particular, encontramos que el robo a vehículos es más sensible a cambios en la tasa de desempleo cuando ésta es menor que la media del municipio que cuando está por arriba. Una posible interpretación de este hallazgo es que en la medida en que las colonias que presentan bajas tasas de desempleo son también las más prósperas en términos económicos, son más vulnerables al robo de automóviles (y autopartes) cuando el desempleo aumenta. Esto no ocurre en las colonias donde la tasa de desempleo es mayor a la media municipal, ya que un aumento en dicha tasa lleva a un menor aumento en los robos de vehículos.

Nuestros resultados también sugieren que en el caso de robos de automóviles existen ciertas diferencias intermunicipales: los municipios de Tonalá y Zapopan son menos propensos a presentar robos de vehículos que Guadalajara. Acerca de la relación entre algunas de las características sociodemográficas y la delincuencia, algunos hallazgos resultan interesantes. Por un lado, las colonias que presentan un mayor número de personas en la tercera edad son más proclives a presentar más robos de vehículos. De la misma manera, las colonias con un mayor número de personas con sólo educación básica (primaria y secundaria) presentan un menor número de robos de vehículos.

${ }_{9}$ Otras de las posibles causas son la pobre calidad de los datos, la mala especificación del modelo econométrico a estimar, etc. (Greene, 1993). 
El indicador de bienestar de la colonia es estadísticamente significativo $\mathrm{y}$ es positivo. Esto sugiere que las colonias que tienen mayores niveles de bienestar (o riqueza) son más propensas a sufrir robos de vehículos. Se debe notar que a nivel colonia se encontró una alta correlación entre el nivel de bienestar y el número de personas con estudios mayores a preparatoria, lo cual determinó no incluir este nivel educativo en el análisis econométrico. Las colonias donde el número de personas que viven en hogares uniparentales de género femenino presentan menor tendencia a enfrentar este tipo de robo. Por último, encontramos cierta evidencia de que las colonias de mayor tamaño (con más de 5000 habitantes) son más proclives a presentar más robos de vehículos. A mayor tamaño de la colonia, mayor es la tendencia a este tipo de robos.

En el caso de robo a personas, la evidencia acerca de la existencia de asimetría no es tan definitiva como en el caso anterior (robos de vehículos y autopartes). Según los estimados que se presentan en el Cuadro 8, aun cuando se encuentra evidencia de que los impactos de la tasa de desempleo sobre los robos a las personas difieren según se trate de tasas por arriba o por debajo de la media municipal (véase el modelo 1), el coeficiente de tasa de desempleo por debajo de la media pierde significancia estadística conforme se incluyen las variables sociodemográficas.

Los modelos 5 y 6 son los más completos ya que incluyen las variables sociodemográficas más significativas. Igual que en el caso de robos de vehículos, encontramos que las colonias con mayor número de personas de la tercera edad son más propensas a sufrir robo a personas. En lo que respecta a la educación, ésta resultó significativa. La sensibilidad de los robos por nivel educativo aumenta conforme éste es mayor. A primera vista, tal resultado parece contrario a los hallazgos de otros estudios, que encuentran una relación inversa entre el nivel educativo y la delincuencia, pero si lo analizamos desde la perspectiva de que se trata de delitos denunciados por las víctimas, entonces nuestros resultados son coherentes: las colonias con más personas con mayor nivel educativo son al mismo tiempo las que poseen un mayor nivel de bienestar, lo cual las hace atractivas para los delincuentes.

Por otro lado, las colonias con un mayor número de mujeres son menos propensas a sufrir robos a personas. De igual manera, encontramos que las colonias que tienen más viviendas sin electricidad presentan una mayor tendencia a tener este tipo de robos. Por último, se encuentra evidencia de que el robo a personas es menor en las colonias cuya población es menor a 5000 personas. 


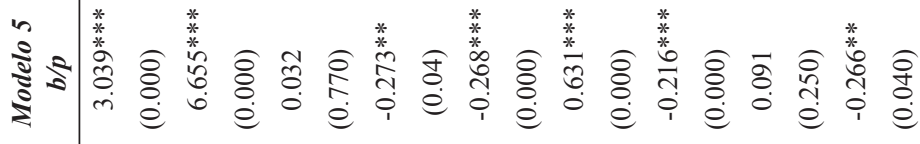

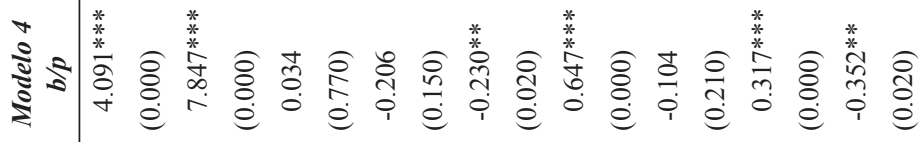

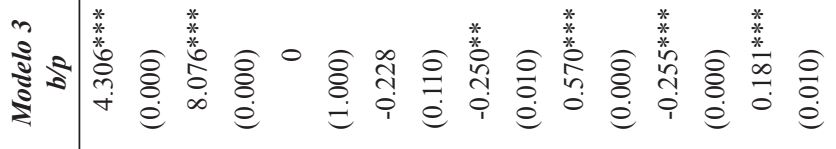

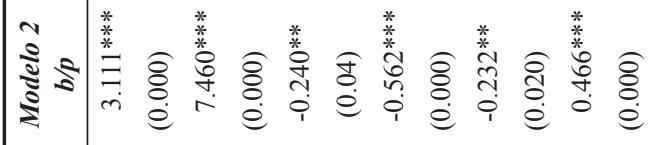

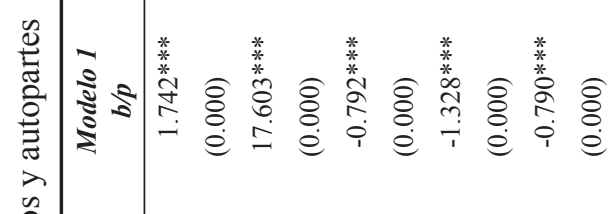

$$
\begin{aligned}
& \text { th }
\end{aligned}
$$

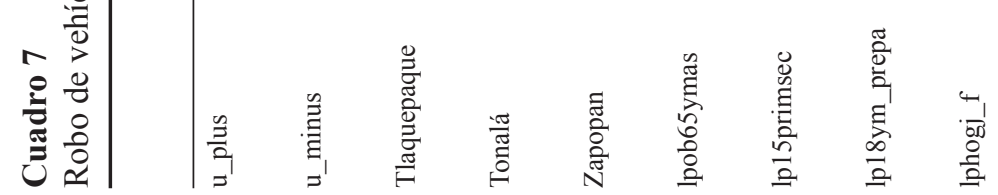




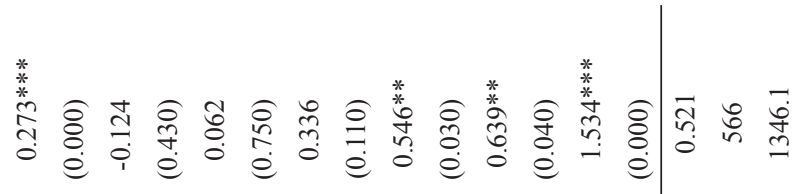

$$
\begin{aligned}
& \text { 옹 }
\end{aligned}
$$

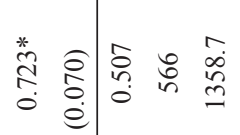

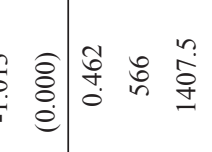

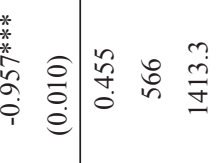

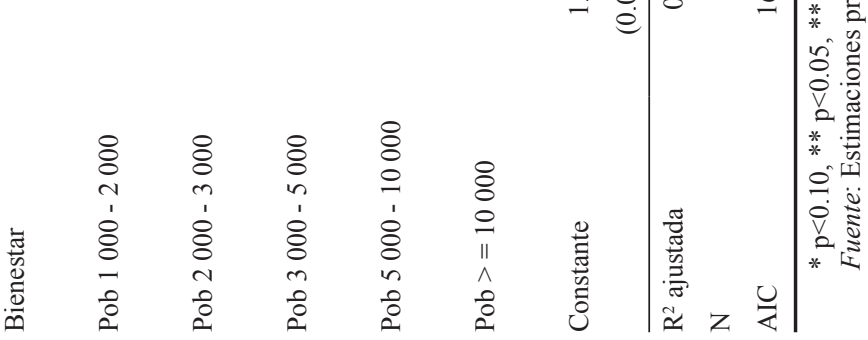

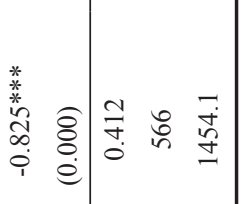

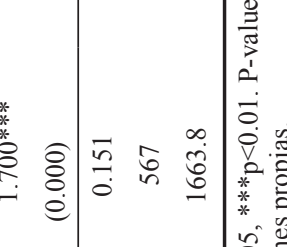




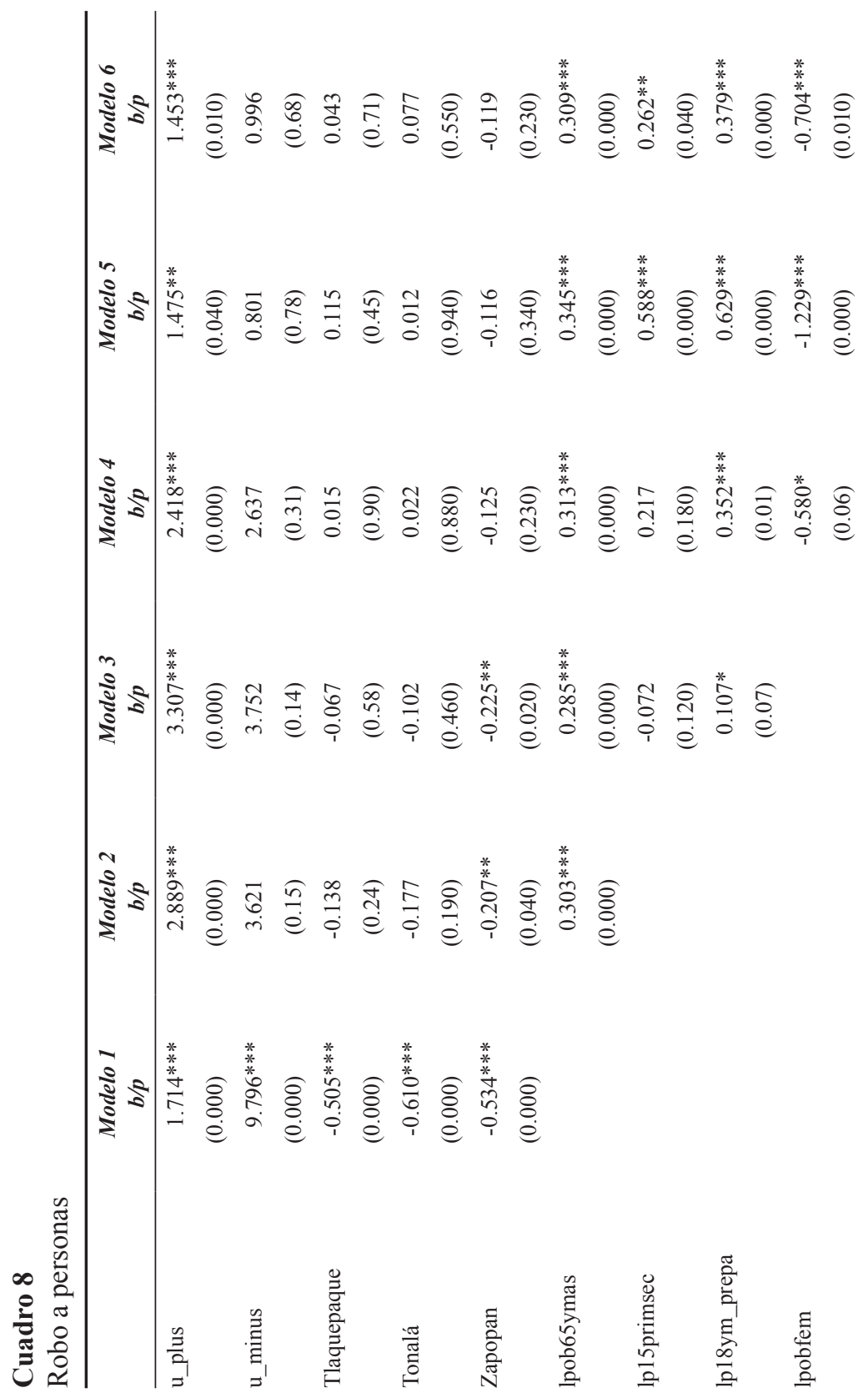




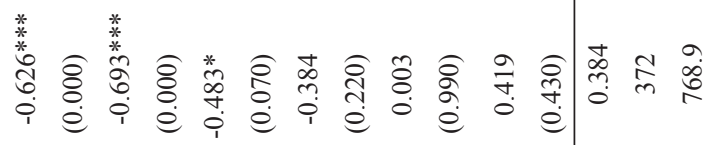

$$
\begin{aligned}
& \text { 홓 } \\
& \text { ֻٕ: }
\end{aligned}
$$

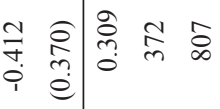

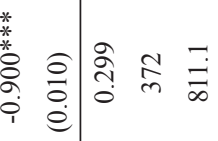

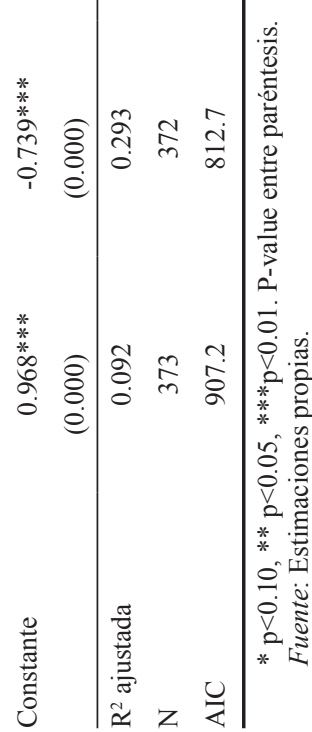

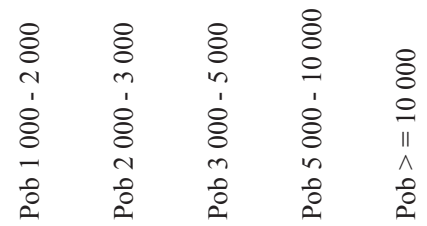


En el Cuadro 9 se presentan los resultados obtenidos para el caso de robo a casas. En primer lugar, aun cuando las estimaciones sugieren la existencia de cierta asimetría, no es estadísticamente significativa. Los modelos 3 y 4 sugieren que al igual que en los dos casos anteriores, la sensibilidad de los robos a casas es menor cuando la tasa de desempleo está por debajo de la media municipal que cuando está por arriba. Al incluir variables adicionales la significancia estadística se pierde, pero el modelo no mejora de manera significativa. El coeficiente de determinación (R2_Adj) pasa de explicar el $37.6 \%$ de la variabilidad de la serie a $42.7 \%$. Por lo tanto, no se puede concluir que existe asimetría en el caso de robo a casas. No se encontró evidencia de diferencias intermunicipales, por lo que se decidió no incluirlas en el cuadro de resultados.

También hay evidencia de que las colonias con mayor proporción de personas en la tercera edad sufren más robos a casas. Las colonias que tienen mayor número de personas con bajos niveles educativos sufren menos robos a casas, mientras que aquellas donde hay más personas con educación superior a preparatoria presentan mayor propensión a robos de este tipo. Estos resultados sugieren que las colonias con mayor nivel de ingreso son más proclives a sufrir tal modalidad de robo, lo cual es corroborado por la significancia estadística y positiva de la variable bienestar.

Por otro lado, encontramos evidencia significativa y positiva entre el número de personas que no tienen acceso a servicio social con el número de robos a casas. En este caso, el tamaño de la colonia sí importa; es decir, mientras más grande es la colonia, mayor es la propensión a sufrir robo a casa habitación.

El Cuadro 10, el último, presenta los resultados cuando se agregan los tres tipos de robos, más los perpetrados a bancos e instituciones financieras, cajeros automáticos y a negocios, entre otros tipos de delitos contra la propiedad. Debido a la naturaleza propia de los robos a bancos y a negocios, la evidencia a favor de la asimetría es menos clara. La inclusión de estos otros tipos de robos hace que se pierda el efecto del desempleo. Sin embargo, el papel que juegan los determinantes sociodemográficos se mantiene. Las colonias con una alta proporción de personas de la tercera edad siguen siendo más propensas a los delitos contra la propiedad; lo mismo que las colonias con una mayor proporción de personas con educación superior a preparatoria. De igual manera, las colonias con mayor presencia femenina son menos propensas a presentar delitos contra la propiedad. La falta de energía eléctrica también incide sobre el total de ese tipo de delitos de manera positiva; lo mismo ocurre en las colonias con mayor número de personas que no tienen acceso a la seguridad social. 


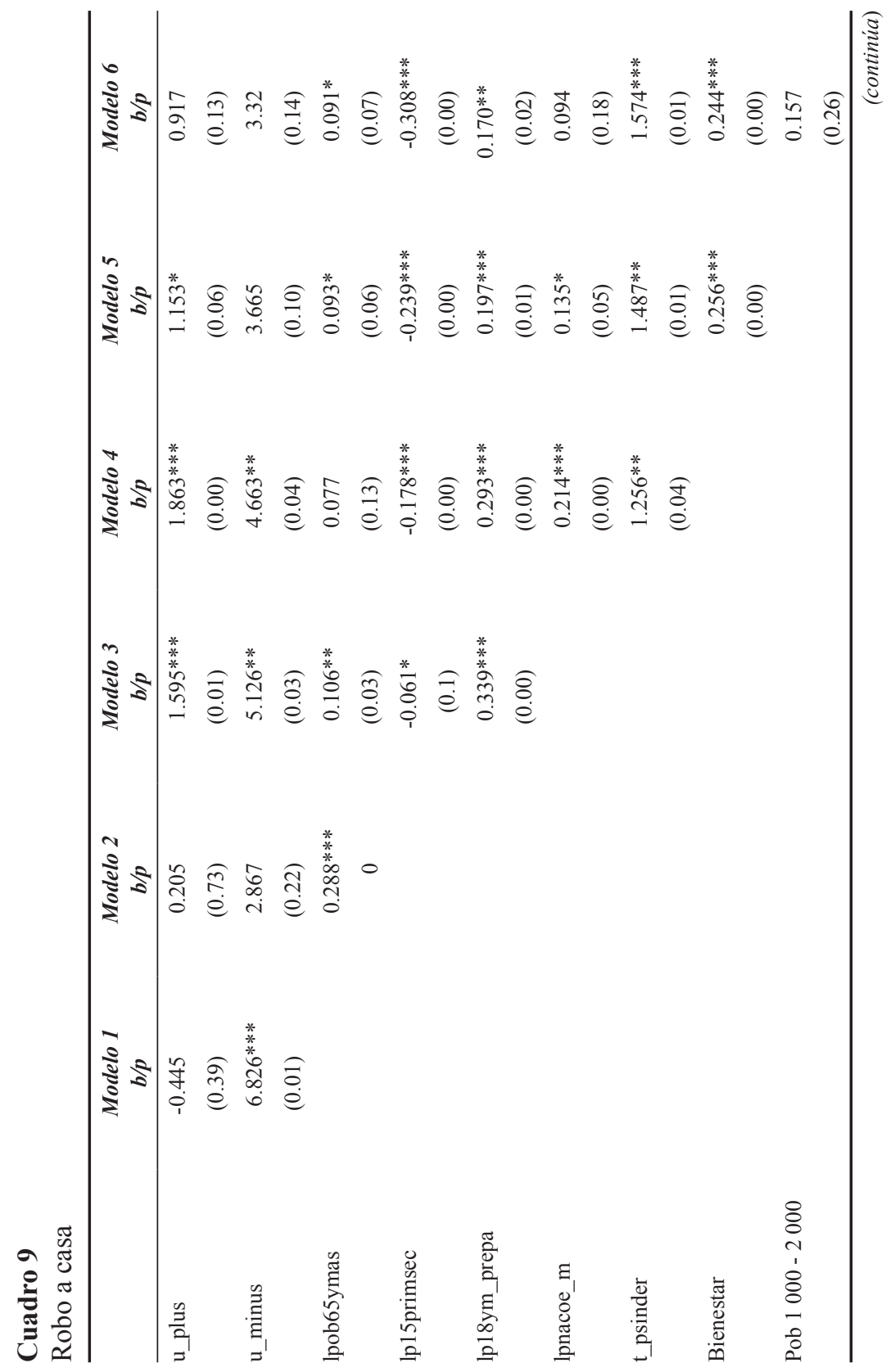




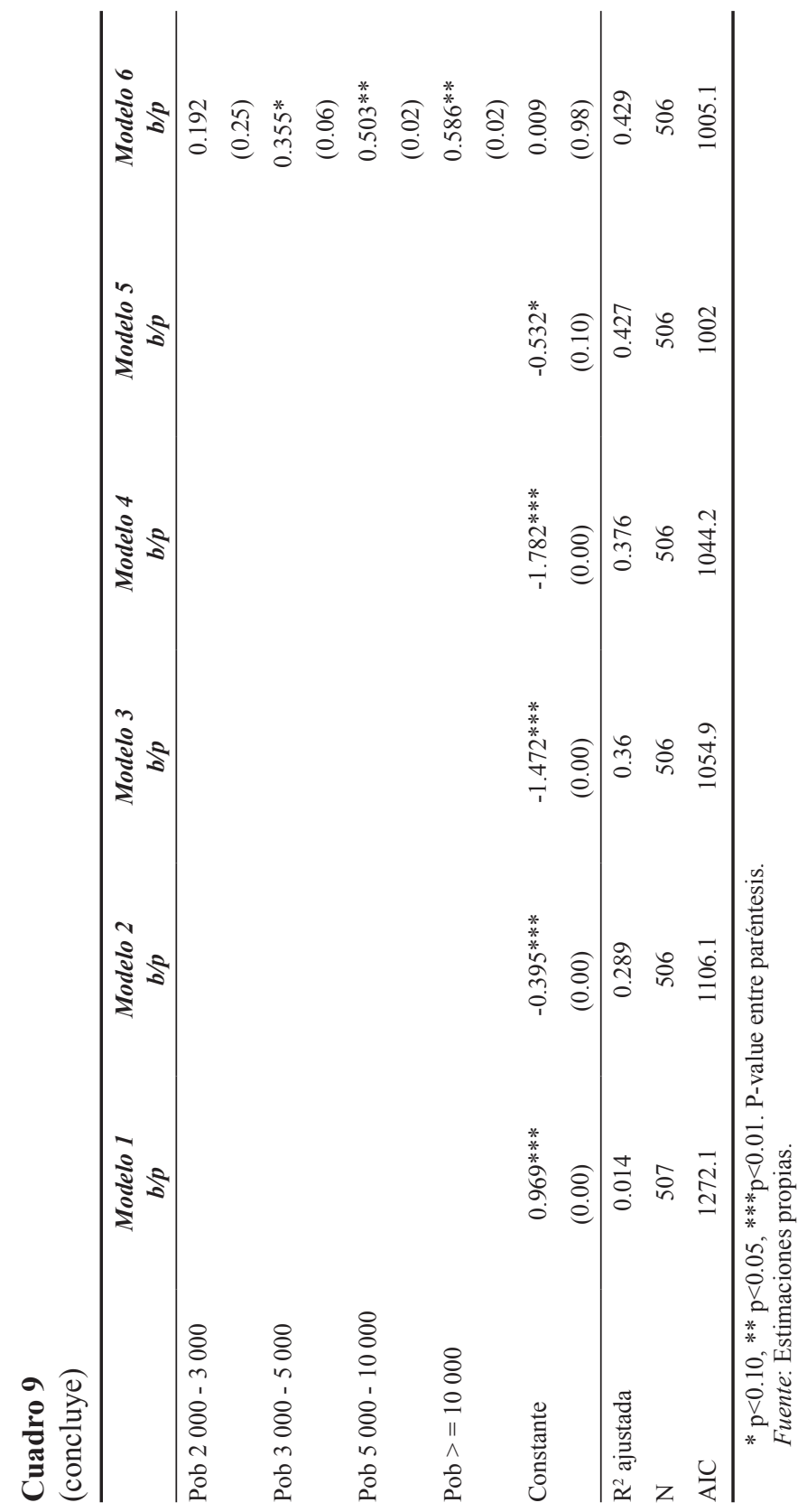




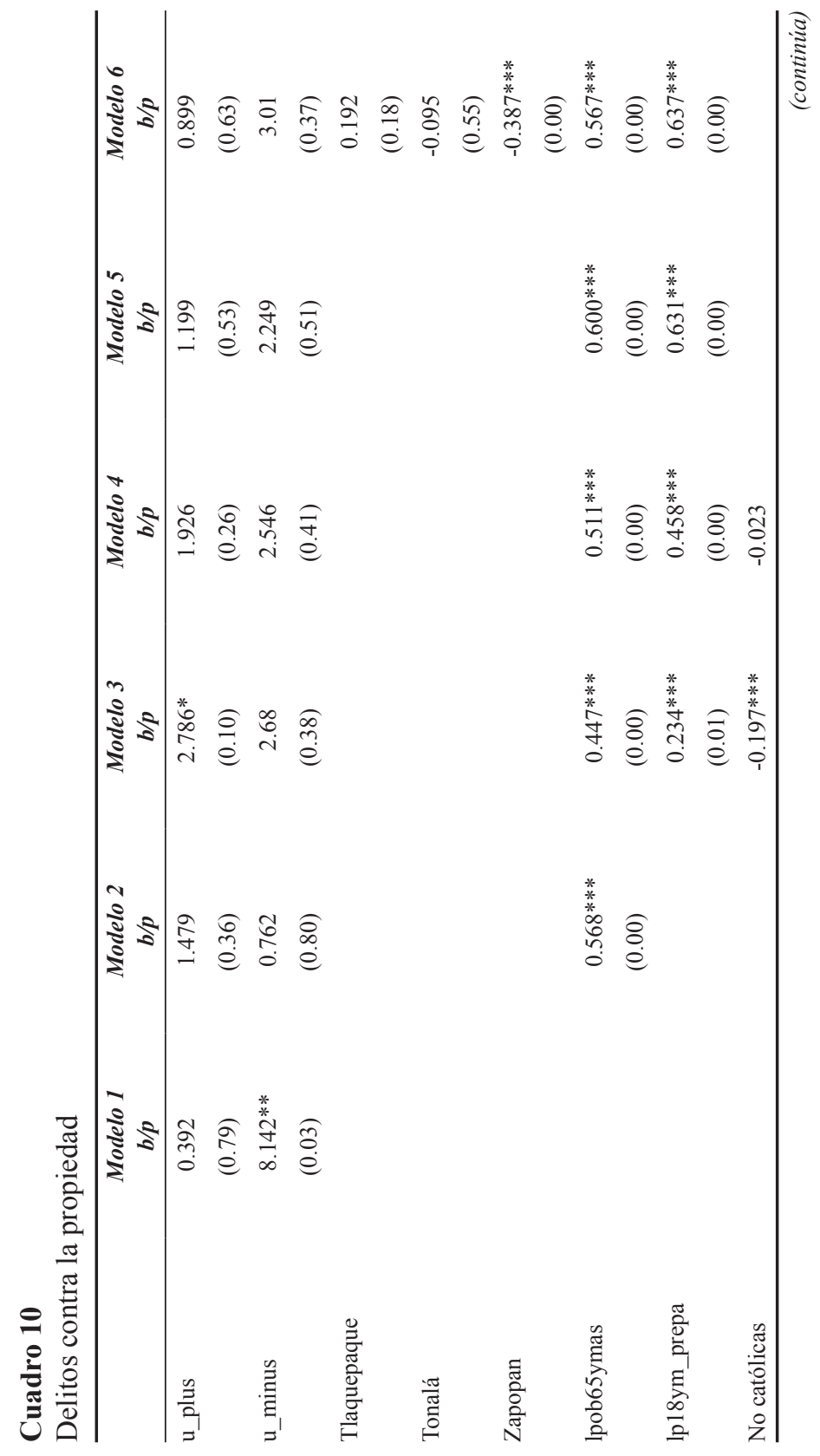




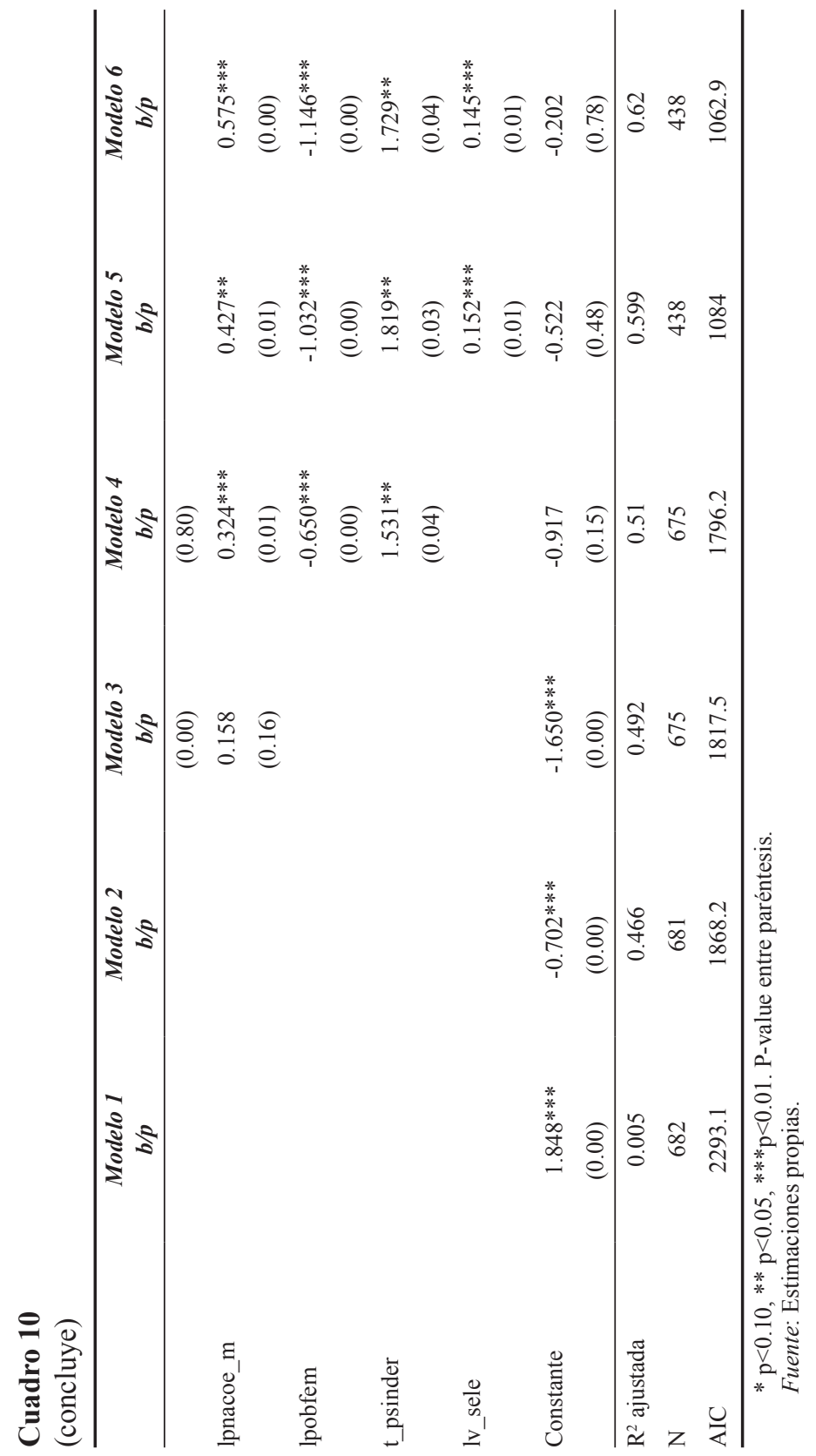




\section{A manera de conclusión}

Al hacer una modificación al modelo propuesto por Mocan y Bali (2005) tratamos de evaluar la presencia de asimetría en los robos en la ZMG. En nuestro estudio la asimetría se mide como la respuesta de los delitos a cambios en las condiciones económicas cuando la tasa de desempleo de la colonia se encuentra por arriba o por debajo de la media municipal, controlando por un conjunto de variables que han sido identificadas en estudios previos como determinantes de la delincuencia.

Uno de los grandes obstáculos al que nos enfrentamos es la falta de información de las variables socioeconómicas y demográficas a nivel colonia para diversos años. Esta carencia condicionó nuestro estudio a ser un análisis de sección cruzada para un solo año, 2010. Como sabemos, uno de los problemas más comunes que los estudios de sección cruzada enfrentan es el de la heteroscedasticidad. Se tomaron algunas medidas que ayudaron a reducir el problema significativamente: la aplicación del logaritmo de la variable dependiente y la estimación de los parámetros utilizando el estimado robusto de la matriz de varianza-covarianza (método Huber/White en STATA $^{\mathrm{TM}}$ ). Se hace esta aclaración para poder interpretar nuestros resultados como preliminares.

Un reflejo de la histéresis es la existencia de una respuesta asimétrica de la delincuencia ante los cambios de sus variables explicativas. En ese sentido, se evalúa la respuesta de los robos frente a los cambios en las condiciones económicas de la colonia. Para ello se hace una modificación al modelo propuesto por Mocan y Bali (2005). En nuestro estudio, la asimetría se mide como la respuesta de los delitos a los cambios en la tasa de desempleo cuando éstos se encuentran por arriba o por debajo de la media municipal, controlando por un conjunto de variables que han sido identificadas en estudios previos como determinantes de la delincuencia.

Recapitulando nuestros principales resultados, al asociar las denuncias de robos a nivel colonia en la ZMG con factores socioeconómicos y demográficos, encontramos evidencia de que la tasa de desempleo tiene un efecto asimétrico sobre estos delitos. Sin embargo, este efecto no es homogéneo para todos los tipos de robos: algunos son más sensibles al efecto, como es el caso de los robos de automóviles. Cuando se agregan todos los tipos de robos, la evidencia en favor del efecto diferenciado de la tasa de desempleo se pierde por la variedad de delitos considerados.

Encontramos suficiente evidencia que -en los casos de robo de autos y autopartes y a las personas-, éstos son más sensibles a los cambios en la tasa de desempleo cuando la colonia presenta tasas por debajo de la media de su 
municipio que cuando están por arriba de la media de éste. Para el caso del robo a casa habitación, aun cuando encontramos evidencia de la existencia de asimetría, ésta se pierde cuando se controla por nivel de bienestar y tamaño de la colonia: las más prósperas son al mismo tiempo las que presentan las tasas de desempleo más bajas y más grandes.

También se encontró que las colonias con mayor número de personas de la tercera edad (i.e., mayores de 65 años) son más propensas a sufrir robos. Encontramos resultados mixtos acerca de la relación entre la variable educación y el delito: los bajos niveles educativos (primaria y secundaria) están asociados con menores niveles de robos, mientras que los niveles educativos altos (preparatoria, universidad y posgrado) están asociados positivamente con los robos. Existen algunas posibles interpretaciones de este hallazgo. Primera, que las personas con mayores niveles educativos sean más proclives a presentar denuncias de delitos cuando son víctimas de alguno de ellos, lo cual explicaría la relación positiva entre niveles altos de educación y delitos. Segundo, las personas con mayor nivel educativo son más propensas a sufrir delitos, mientras que las personas con menor nivel no lo son. Tercera, que tal relación sea el resultado de ambos fenómenos: a mayor nivel educativo, mayor denuncia y mayor victimización.

Se trató de evaluar si los robos tenían alguna relación con el género de la población. Contrario a la percepción generalizada de que las mujeres son más propensas a ser víctimas de delitos, se encontró que para el caso del robo a personas, las colonias con mayor número de mujeres presentan menos denuncias de este tipo. También se encontró una relación negativa entre los hogares uniparentales femeninos y la delincuencia en el caso de robo de autos. Finalmente, el tamaño de la colonia sólo resultó significativo en el caso del robo a casa y en el de automóviles: hay una mayor tendencia de estos delitos en colonias de más de 5000 personas. En términos generales, las diferencias intermunicipales no juegan un papel determinante en la ocurrencia de tales ilícitos.

Con base en nuestros resultados es posible delinear algunas recomendaciones para la implementación de una política antirrobos más efectiva. La magnitud del efecto histéresis indica que los delitos no son aleatorios, que ocurren en determinadas áreas con bastante regularidad. Adicionalmente, las características idiosincráticas de las colonias determinan el tipo de robo que prevalece en ellas. Esto puede ayudar en el diseño de políticas de seguridad más efectivas. 


\section{Bibliografía}

Becker, Gary (1968), “Crime and punishment: An economic approach", Journal of Political Economy, vol. 76, núm. 2. Disponible en: http://www.journals.uchicago. edu/doi/pdfplus/10.1086/259394

Bourguignon, François (2001), "Crime as a social cost of poverty and inequality: A review focusing on developing countries", en Shahid Yusuf, Simon Evenett y Wu Weiping (eds.), Facets of globalization. International and local dimension of development, World Bank Discussion Paper, núm. 415, Washington, DC, Banco Mundial. Disponible en: http://hdl.handle.net/10986/14014

DANE (2012), Encuesta de Convivencia y Seguridad Ciudadana, Bogotá, Departamento Administrativo Nacional de Estadística.

Demombynes, Gabriel y Berk Özler (2002), "Crime and local inequality in South Africa", World Bank Policy Research Working Paper, núm. 2925. Disponible en: https://papers.ssrn.com/sol3/papers.cfm?abstract_id=636287

Gaviria, Alejandro y Carmen Pagés (1999), "Patterns of crime victimization in Latin America", Working Paper, núm. 408, Washington DC, Inter-American Development Bank, Research Department. Disponible en: http://services.iadb.org/ wmsfiles/products/Publications/788226.pdf

Glaeser, Edward, Bruce Sacerdote y José Scheinkman (1996), "Crime and social interactions", The Quarterly Journal of Economics, vol. 111, núm. 2, pp. 507548. Disponible en: http://econpapers.repec.org/article/oupqjecon/v_3a111_3ay _3a1996_3ai_3a2_3ap_3a507-548..htm

Glaeser, Edward y Bruce Sacerdote (1999), "Why is there more crime in cities", Journal of Political Economy, vol. 107 (S6), pp. S225-S258. Disponible en: http://www.antoniocasella.eu/nume/glaeser_sacerdote_1999.PDF

Greene, William H. (1993), Econometric Analysis, Englewood Cliffs, NJ, Prentice Hall.

ICESI (2009), "Victimización, incidencia y cifra negra en México", Análisis de la ENSI, núm. 6, Ciudad de México, Instituto Ciudadano de Estudios sobre la Inseguridad A.C. Disponible en: https://es.slideshare.net/PUDHUNAM/mexicoanalisis-ensi6

Instituto Nacional de Estadística (2015), Estadística de Seguridad Ciudadana, Lima, Instituto Nacional de Estadística.

INEGI (2016), Censo de Población y Vivienda, 2010. Microdatos, México, Instituto Nacional de Estadística y Geografía. Disponible en: http://www.beta.inegi.org. $\mathrm{mx} /$ proyectos/ccpv/2010/

Johnston, Jack y John DiNardo (1997), Econometric methods, Nueva York, The McGraw-Hill Companies.

Loureiro, André (2013a), "Essays on crime, hysteresis, poverty and conditional cash transfers", tesis de doctorado, Edimburgo, The University of Edinburgh.

Loureiro, André (2013b), "Asymmetric effects and hysteresis in crime rates: Evidence from United States”, Edimburgo, University of Edinburgh (mimeo.). Dispo- 
nible en: http://docplayer.net/12278998-Asymmetric-effects-and-hysteresis-incrime-rates-evidence-from-the-united-states.html.

Ministerio del Interior y Seguridad Pública e Instituto Nacional de Estadísticas (2013), Encuesta Nacional Urbana de Seguridad Ciudadana, Santiago de Chile, MISP / INE.

Mocan, Naci y Turan Bali (2005), "Asymmetric crime cycles", National Bureau of Economic Research Working Paper, núm. 11210, Cambridge, MA, National Bureau of Economic Research. Disponible en: http://www.nber.org/papers/ w11210.pdf

Navarro, Jose y Willy W. Cortez (2015), "Who are the victims of property crime in Mexico?”, International Journal of Social Economics, vol. 42, núm. 2, pp. 179198. Disponible en: http://www.emeraldinsight.com/doi/pdfplus/10.1108/IJSE05-2013-0122

Patterson, Britt (1991), "Poverty, income inequality, and community crime rates", Criminology, vol. 29, núm. 4, pp. 755-776. Disponible en: http://onlinelibrary. wiley.com/doi/10.1111/j.1745-9125.1991.tb01087.x/epdf

PGJEJ (2016), "Estadísticas de alto impacto en la Zona Metropolitana de Guadalajara", Guadalajara, Procuraduría General de Justicia del Estado de Jalisco (Estadísticas).

Soares, Rodrigo y Joana Naritomi (2010), "Understanding high crime rates in Latin America: The role of social and policy factors", en Rafael Di Tella, Sebastian Edwards y Ernesto Schargrodsky (eds.) (2010), The economics of crime. Lesson for and from Latin America, Chicago, National Bureau of Economic Research / The University of Chicago Press.

OEA (2005), Encuesta Internacional de Criminalidad y Victimización, Washington, D.C., Organización de los Estados Americanos.

Vergara, Rodrigo (2009), "Crime prevention programs: Evidence for a developing country", Working Paper, núm. 362, Santiago de Chile, Pontificia Universidad Católica de Chile, Instituto de Economía, Disponible en: http://economia.uc.cl/ docs/dt_362.pdf

Weibull, Jörgen y Edgar Villa (2005), "Crime, punishment and social norms", Working Paper Series in Economics and Finance, núm. 610, Estocolmo, Stockholm School of Economics. Disponible en: http://swopec.hhs.se/hastef/papers/hastef 0610.pdf

\section{Acerca del autor}

Willy W. Cortez es doctor en Economía por la Universidad de Notre Dame, Estados Unidos. Actualmente es profesor de tiempo completo del Departamento de Métodos Cuantitativos de la Universidad de Guadalajara. Ha sido coordinador de la maestría en Economía de la misma universidad y fue miembro fundador y primer director de la revista EconoQuantum. Ha publi- 
cado en World Development, CEPAL Review, Estudios Económicos, Investigaciones Económicas, entre otras revistas. Es miembro del Sistema Nacional de Investigadores, nivel III. Sus líneas de investigación giran en torno al crecimiento económico, la desigualdad en la distribución del ingreso, el mercado laboral y el desempeño macroeconómico y economía del crimen.

Fecha de recepción: 6 de septiembre de 2016.

Fecha de aceptación: 9 de mayo de 2017. 
